\title{
A Holistic-Comprehensive Approach: Best Practices to Improve Health Policy for COVID-19 Pandemic
}

\author{
Febri E B Setyawan ${ }^{1 *}$, Retno Lestari²
}

\begin{abstract}
${ }^{1}$ Department of Family, Industrial and Islamic Medical Sciences, Faculty of Medicine, University of Muhammadiyah Malang, Indonesia
2Department of Mental Health Nursing, Faculty of Medicine, University of Brawijaya, Malang, Indonesia
\end{abstract}

\begin{abstract}
The COVID-19 pandemic affects entire communities and causes a huge impact on all life aspects which include biological, psychological, social, and spiritual well-being. Health systems and health policies are promising developments and opportunities to review progress and accelerate interventions in COVID-19 control. Studies devoted to core holistic-comprehensive issues surrounding this pandemic are limited. Therefore, this article aimed to review several best practice studies that reflect holistic-comprehensive approaches to COVID-19. A comprehensive literature review was written based on 15 articles from the data sources which are Google Scholar, Science Direct, ProQuest Health, and Medical Complete, and ProQuest Science Journals from 2010 to 2020 , searched terms related to holistic, comprehensive, outbreak, pandemic, epidemics, and COVID-19. There are many evidence-based practices on safe and effective strategies to improve all aspects of well-being before, during, and after the COVID-19 pandemic. Among these promising strategies, a holistic-comprehensive approach could also be considered as a necessary action to improve health policy during the pandemic. A holistic-comprehensive approach involved providing bio-psycho-socio-spiritual care and offered a continuum of healthcare that provides promotive, preventive, curative, and rehabilitative services. A holistic-comprehensive approach to the COVID-19 pandemic requires a sustained commitment from entire communities, stakeholders, and policymakers to achieve better health outcomes for all.
\end{abstract}

Keywords: Coronavirus, health policy, holistic-comprehensive, pandemic

\section{Introduction}

The current coronavirus disease 2019 (COVID-19) pandemic in many countries is expected to diminish over the coming months. This pandemic situation also affects entire communities and causes a huge impact on all life aspects which include biological, psychological, social, and spiritual well-being. Health systems and health policies are promising developments and opportunities to review progress and accelerate interventions in COVID-19 control.

The best practices and guidelines shared throughout the world demonstrate that several interventions to control this infectious disease are possible. There are many evidence-based practices on safe and effective strategies to improve all aspects of well-being before, during, and after the COVID-19 pandemic. Among these promising strategies, a holistic-comprehensive approach could also be considered as a necessary action to improve health policy during the pandemic. A holistic-comprehensive approach involved the provision of bio-psycho-socio-spi-

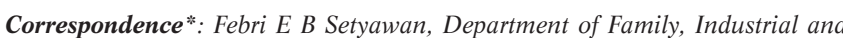
Islamic Medical Sciences, Faculty of Medicine, University of Muhammadiyah Malang, Malang, Indonesia 65145, E-mail: febri@umm.ac.id, Phone: +62-341552443 ritual care and offered a continuum of health care: promotive, preventive, curative, and rehabilitative services. 1,2

A holistic-comprehensive approach is intended to address the challenges of bringing healthcare services in more direct and comprehensive care during the pandemic. Assessment of all potential determinant factors that influence health status in individuals, families, and communities should be addressed. ${ }^{3,4}$ Studies demonstrated factors related to the outcomes of COVID-19, including the immune responses, age, sufficient treatment, and socioeconomic factors. Recent estimates suggest that social and economic change contributed to the rapid spread of COVID-19 pandemic, for instance, social and demographic characteristics, public health infrastructure, health statistics, economic development, and environmental quality. ${ }^{5-7}$ The culture of society also influenced the psychological response to the pandemic and their willingness to manage mental health issues. ${ }^{8}$ Hence, it is important to understand the individual as a whole person 
not just as a patient or diagnosis.

A holistic perspective in health policy means that addressing health determinant factors at all levels is important to organize and develop goal-directed comprehensive interventions for COVID-19. There were five main elements in holistic policy: (1) considering the whole individuals and the interactions between the social systems, (2) comprehensive understanding of other risk factors related to health, such as psychology, culture and socioeconomic status, (3) developing community partnerships, creating reciprocal relationships and establishing open communication, (4) increasing collaborative practice for health promotion, and (5) improving sustainability in health systems and healthcare. ${ }^{9}$

A previous study investigated the benefits of using holistic health management during the Ebola outbreak in West Africa. They found that health systems should include efforts to incorporate cultural beliefs and practices when determining strategies during an outbreak. The findings revealed that a holistic approach for comprehensive care is needed to address the challenges of emerging infectious diseases. ${ }^{10}$ Studies devoted to core holisticcomprehensive issues surrounding this pandemic are limited. Therefore, this article aim to review several best practice studies that reflect holistic-comprehensive approaches to COVID-19.

\section{Method}

A comprehensive literature review was performed to retrieve recent articles addressing holistic-comprehensive approaches related to COVID-19 treatment. Although there is no standardized consensus on this type of literature review, we have tried to critically evaluate articles and provide suggestions for future research by using the Preferred Reporting Items for Systematic Reviews and Meta-Analyses (PRISMA) flow diagram. This study was written based on 15 articles from the data sources that were Google Scholar, Science Direct, ProQuest Health, and Medical Complete, and ProQuest Science Journals from 2010 to 2020, searched terms related to holistic, comprehensive, outbreak, pandemic, epidemics, and COVID-19. In addition to this, all articles were then screened to determine their relevance.

Articles meeting these criteria were included if articles were peer-reviewed, using the English language between 2010 and 2020, presented empirical studies related to COVID-19 (quantitative and qualitative), and investigated holistic-comprehensive approaches to pandemic, outbreak, and epidemic.

A total of 50 articles were retrieved and then screened based on inclusionary criteria (Figure 1). Of this number, the study revealed 20 articles that met the inclusionary and exclusionary criteria. The study which had incomplete information was automatically excluded. Significant articles were selected and only 15 articles obtained to be reviewed (Table 1). Relevant policy related to COVID19 was identified by reviewing selected articles, and reports related to best practices to implement a holisticcomprehensive approach. Best practices research aimed to describe any practices as alternatives to improve the management by implementing strategies that are more successful in the relevant fields. ${ }^{11}$

Any relevant articles presenting evidence (whether primary or secondary) on holistic-comprehensive approaches were also included in the analysis. Additionally, this study was complemented by grey literature reviews from newspapers' reports, government websites with regards to rules and regulations, and current situation updates on COVID-19. We describe best practices studies that reflect holistic-comprehensive approaches to COVID-19 based on the Centers for Disease Control and Prevention (CDC) before, during, and after the pandemic.

\section{Results}

Table 1 describe best practices studies that reflect holistic-comprehensive approaches to COVID-19 based on $\mathrm{CDC}$ before, during, and after the pandemic. Any rele-
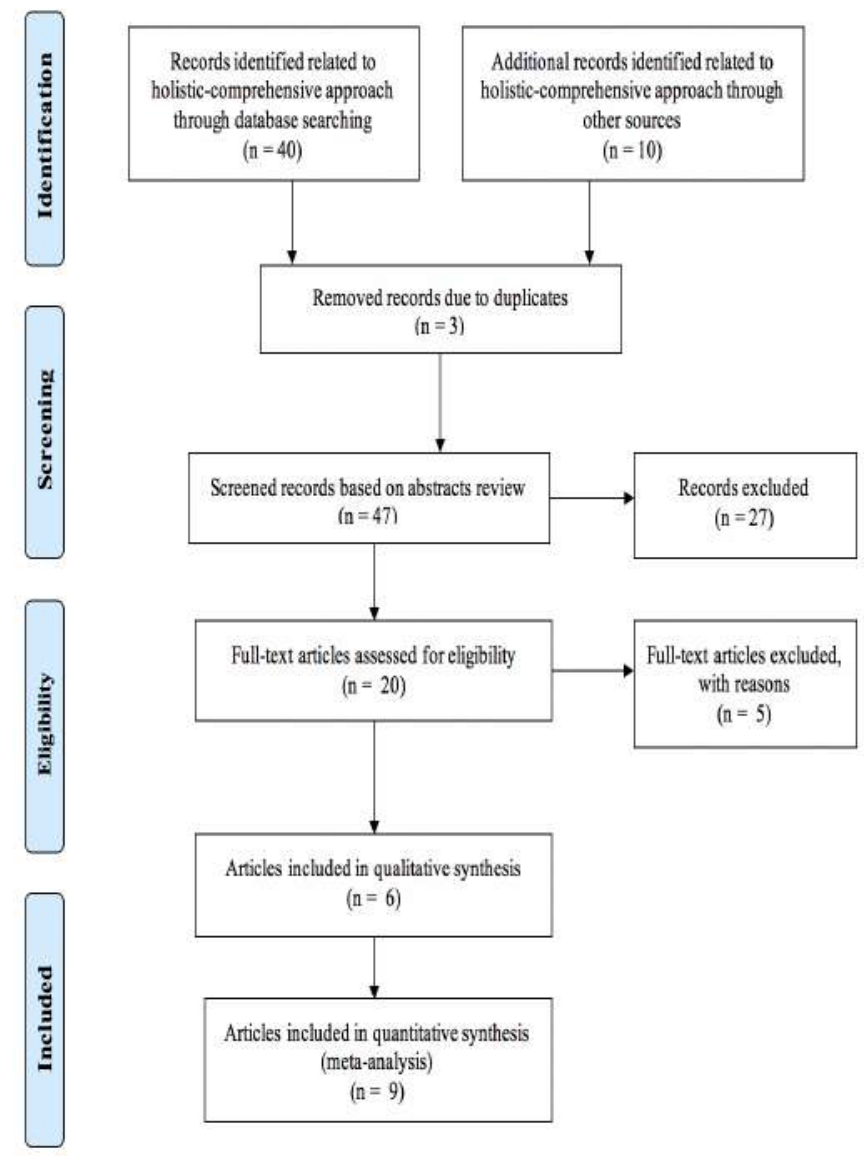

Figure 1. PRISMA Flow Diagram of the Articles Selection Process 
Table 1. Literature Review

\begin{tabular}{|c|c|c|c|}
\hline Study & Reference (Year) & Study Design & Result \\
\hline 1 & Saha, et al., ${ }^{19}$ (2018) & Retrospective surveillance & $\begin{array}{l}\text { Epidemiology characteristics may affect the interpretation } \\
\text { of disease burden }\end{array}$ \\
\hline 2 & Shen, et al., ${ }^{27}$ (2015) & Mathematical model & $\begin{array}{l}\text { Patient isolation may not always have a contribution in } \\
\text { controlling disease transmission }\end{array}$ \\
\hline 3 & Pan, et al. 35 (2020) & Cohort study & Public health strategies improved COVID-19 management \\
\hline 4 & Njuguna, et al.,21 (2019) & Surveillance & $\begin{array}{l}\text { An integrated surveillance system to help recover from } \\
\text { Ebola crisis }\end{array}$ \\
\hline 5 & Arslantas, et al., 31 (2019) & Modeling a holistic framework & $\begin{array}{l}\text { Hazard exposure, vulnerability, poor coping skills, socio- } \\
\text { economic factors increased disease risk }\end{array}$ \\
\hline 6 & Abdulkareem, et al., 32 (2020) & Modeling intelligent learning & Social learning was affected by social and cultural norms \\
\hline 7 & Kinsman, et al.,23 (2018) & Case study & Preparedness and response plans during an epidemic \\
\hline 8 & Afayo, et al., ${ }^{24}$ (2019) & Cross-sectional study & $\begin{array}{l}\text { The gap between preparedness and response to the out- } \\
\text { break }\end{array}$ \\
\hline 9 & Craig, et al., ${ }^{20}$ (2018) & Surveillance & The surveillance system is a priority during the outbreak \\
\hline 10 & Sepers, et al., ${ }^{34}$ (2018) & Participatory study & Needs a comprehensive monitoring and evaluation system \\
\hline 11 & Alonge, et al., ${ }^{18}$ (2019) & Interviews with stakeholders & $\begin{array}{l}\text { Leadership, social bonding, trusted information, social } \\
\text { trust affected community resilience during the outbreak }\end{array}$ \\
\hline 12 & Rabelo, et al.,28 (2016) & Focus group discussions & Feeling worried, lack of respect, motivation, hope, isolated \\
\hline 13 & Siu, et al., 30 (2016) & Phenomenology & Sociocultural factors using personal protective equipment \\
\hline 14 & Respati, et al., ${ }^{14}$ (2018) & Focus group discussion & $\begin{array}{l}\text { Eco-health model: prevention, community engagement, } \\
\text { environment, and climate }\end{array}$ \\
\hline 15 & Loignon, et al., ${ }^{17}$ (2018) & $\begin{array}{l}\text { In-depth semi-structured } \\
\text { interviews }\end{array}$ & $\begin{array}{l}\text { Barriers in supportive care: lack of resources, restricted to } \\
\text { deliver supportive care, poor coordination }\end{array}$ \\
\hline
\end{tabular}

vant articles presenting evidence (whether primary or secondary) on holistic-comprehensive approaches were also included in the analysis. Additionally, this study was complemented by grey literature reviews from newspapers' reports, government website with regards to rules and regulations, and current situation updates on COVID-19.

\section{Discussion}

\section{A holistic-comprehensive of care}

COVID-19 can be well managed through holistic planning using a multi-sectoral and comprehensive approach - "Detect, Develop, Deliver". In China, researchers detected the genome sequence of COVID-19, and this investigation was then reported to the WHO, allowing all researchers in the world to develop the vaccines. Developing COVID-19 treatment needs a multisectoral approach to help with financial budgeting. Additionally, the government should support social and economic changes as the impact of lockdown and workfrom-home policy. In response to COVID-19, the Government of Singapore provided \$ 55 million as financial support for 40,000 drivers. ${ }^{12}$ In Indonesia, the government took immediate action to assist Indonesian civil society through Family Hope Program (IDR 37.4 trillion), Social Assistance for Staple Food (IDR 2.2 trillion), Village Fund (IDR 21 trillion), Cash LaborIntensive Program (IDR 16.9 trillion), and PreEmployment Card Program (IDR 360 billion). ${ }^{13}$

A comprehensive system of care delivery is needed, so people can have access to the continuum of care.
Engaging communities to support and comply with the health policy is needed to achieve sustainability of program. ${ }^{14}$ Strengthening public health infrastructure and social networks is essential during the pandemic. Learning from Wuhan is important as they can build 27 hospitals and engage 2,000 workers to prepare for the other two hospitals for treating COVID-19 patients. ${ }^{12}$ In Indonesia, almost all the hospitals could deliver appropriate treatment for COVID-19 patients, from conducting a rapid test to comprehensive treatment for COVID19.15

\section{Best practices to implement a holistic-comprehensive approach}

In this study, we described best practices based on a comprehensive literature review to describe and synthesize with regards to holistic-comprehensive approaches related to COVID-19 treatment developed by researchers and clinicians. A holistic-comprehensive approach as best practices to improve health policy for the COVID-19 pandemic was developed and modified according to the CDC, which designed best practices for health professionals to properly respond before, during, and after COVID-19 state of emergency (Table 2). Non-pharmacological approaches were recommended as key messages and actions to address the COVID-19. ${ }^{16}$

As the COVID-19 response begins and ends at the local level, therefore, in the preparedness phase, comprehensive community planning should focus on improving health systems and services, including communications across all levels: leaders, stakeholders, and wider communities. Six components should be taken before prepar- 
Table 2. Best Practices to Implement a Holistic-Comprehensive Approach during the COVID-19 Pandemic

\begin{tabular}{ll}
\hline Period of Pandemic & $\begin{array}{l}\text { Best Practices to Implement a Holistic-Comprehensive } \\
\text { Approach }\end{array}$ \\
\hline Before & $\begin{array}{l}\text { Develop community resilience and recovery after the } \\
\text { outbreak. } \\
\text { Improve coordination of care and connecting individuals } \\
\text { with community resources. } \\
\text { Manage available resources to keep people informed } \\
\text { during the outbreak. } \\
\text { Coordinate the supply of essential medicines. } \\
\text { Increase emergency referral centers during the pandemic. } \\
\text { Evaluate public health surveillance for emerging threats. } \\
\text { Ensure effective communication with the local commu- } \\
\text { nity. } \\
\text { Take appropriate measures to ensure immediate relief } \\
\text { and support being given. } \\
\text { Coordinate emergency resources to support bio-psycho- } \\
\text { socio-spiritual needs. } \\
\text { Develop health policy addressing stigma and mental } \\
\text { health issues. } \\
\text { Evaluate the strategies used to control the outbreak. } \\
\text { Facilitate healthy behavior change. } \\
\text { Build partnerships with stakeholders to strengthen com- } \\
\text { munity capacity and skills. }\end{array}$ \\
After &
\end{tabular}

ing emergency plans: (1) developing community resilience and recovery after the outbreak, (2) improving coordination of care and connecting individuals with community resources as a strategic transformation for better healthcare, (3) managing available resources to keep people informed during the outbreak, (4) coordinating supply of essential medicines, (5) increasing emergency referral centers during the pandemic, and (6) evaluating public health surveillance for emerging threats. ${ }^{16,17}$ To achieve a holistic-comprehensive goal of community planning, thus discussions among the local government and stakeholders are needed in the first weeks of the pandemic. ${ }^{18}$

A holistic-comprehensive surveillance system helps health professionals and policymakers to better understand the pandemic disease and develop public health policy for preventing the spread of infectious disease and promoting health behaviors. Information on the COVID19 collected should include sufficient information on the current state of pandemic disease and the epidemiology of the infectious disease. In a comprehensive surveillance plan, it is also important to identify key populations at increased risk of infectious disease, establish opportunities to manage pandemic, and identify the allocation of resources in the local community as low-income communities were disproportionately affected by the disease. ${ }^{19,20}$

Lesson learned from the cases of Ebola, they built integrated surveillance health systems to strengthen their public health infrastructure, improved early warning systems, increased the capacity of health professionals, pro- vided adequate support and feedback during and after the implementation of programs. ${ }^{21}$ The development of comprehensive planning presumably takes process, and it certainly needs support from whole societies for a successful program.

Before the COVID-19 crisis, there were six main components to consider while developing comprehensive approach: (1) responsive key leaders, (2) multi-sector partnerships and collaboration, (3) comprehensive health surveillance, (4) health education campaigns, (5) health policy to support treatment, and (6) strategies to reduce harm and prevent further crisis. ${ }^{22}$ These key important factors can also be used to develop a holistic-comprehensive health policy to achieving sustainable development goals.

Strengthening pandemic readiness and response to COVID-19 is the key to successful health outcomes. A fast and effective response can delay a local outbreak from becoming a global threat. Before the pandemic, health professionals can work together and create collaboration with the government, civil society, stakeholders, and policymakers to develop community resilience and recovery after the outbreak. We can prepare a program that could strengthen the community, how to respond to COVID-19 issues, and build social networks to support during the crisis. We can improve the coordination of care and connect individuals with community resources. We can manage available resources, such as social media, the internet, and local newspapers to provide trusted information and keep people informed during the outbreak. Coordinating the supply of essential medicines and emergency referral centers is also important as this is the fundamental aspect of care. Public health surveillance for emerging threats is needed to inform disease transmission and prepare for prevention and promotion interventions related to the COVID-19.23,24

Pandemic readiness enables the community to respond effectively to the disease and prepare for future disease outbreak. Well-trained health professionals play a critical role in improving health management and optimizing coordination during the outbreak. Creating effective communication plans was also the key to avoiding false information related to the disease. Further, comprehensive planning in the readiness phase should include resource mobilization, health facilities, and case management for controlling a disease outbreak. ${ }^{25}$

During the outbreak, effective communication is needed between the local community, leaders, stakeholders, and policymakers. World Health Organization (WHO) and CDC have developed basic principles for risk communication and the need to maintain public trust throughout an outbreak. Therefore, health communicators and policymakers should understand the complexities of the pandemic situation and make strategic re- 
sponse plans to the affected populations. ${ }^{26}$ Also, the local community can take appropriate measures to respond to such pandemic and ensure immediate relief and support being given. They can also coordinate emergency resources to support bio-psycho-socio-spiritual needs at a local level.

One of the medical treatments for COVID-19 patients is patient isolation. Isolation precautions are commonly used for patients who are either known or suspected to have a COVID-19. However, a study on the Ebola outbreak investigated that isolation was not always effective in preventing the transmission of infectious disease. Comprehensive treatment was recognized as determining factors in controlling such disease. ${ }^{27}$

As the impact of the pandemic, people may experience psychological symptoms such as fear, anxiety, and grief leads to prejudices against people in the community and stigma. ${ }^{28}$ The stigma associated with COVID-19 is also known as xenophobia, the fears about COVID-19. Stigma was identified as a factor causing inequities in health services and creating a global burden of disease. The fears of COVID-19 are contagious, and it spreads through daily conversations about the pandemic situation. Public mental health systems can be improved if policies to address these issues were put in place. ${ }^{29}$ Therefore, in developing health policy, stigma, and mental health issues as the impact of COVID-19 should be well-addressed. Further, the culture of society affects the psychological response to the pandemic and their willingness to comply with the health policy. ${ }^{8}$ Authors strongly encourage the entire society to support mental health during the crisis. On the other hand, social, economic and cultural factors were determinants of health status during pandemic. ${ }^{30-32}$ In addition to this, WHO provided specific guidance for communities, leaders, health communicators, and mass media to address mental health issues including stigma related to COVID-19.33

After the current pandemic, it is crucial to evaluate strategies used to control the outbreak through comprehensive monitoring and evaluation system. ${ }^{34}$ Health professionals can facilitate changes for healthy behavior by providing the most accurate information through all media sources. The local community can also build partnerships with stakeholders to strengthen the community's capacity and skills for COVID-19. A study in Wuhan showed an improvement when they combined pharmacological treatment and community participation in responding to COVID-19. This study provided a relevant topic with regards to comprehensive approach when dealing with the COVID-19. Several public health strategies were used to combat the disease, even though there was no proven drug or vaccine for COVID-19. It was recommended to improve health policy to influence decision-makers to control the COVID-19 outbreak. ${ }^{35}$
Authors can learn from Wuhan and Ebola cases that comprehensive interventions require all health professionals to collaborate and demonstrate their valuable expertise in disease management.

\section{Conclusion}

Being physically and mentally healthy during the COVID-19 pandemic is important as it helps us to achieve a state of good health. Strengthening pandemic readiness and response to COVID-19, enhancing communication, recognizing and treating physical and psychological needs are keys to success when dealing with the COVID-19. In conclusion, a holistic-comprehensive approach to the COVID-19 pandemic requires a sustained commitment from entire communities, stakeholders, and policymakers to develop programs and multistakeholder cooperation to achieve better health outcomes for all.

\begin{abstract}
Abbreviations
COVID-19: Coronavirus Disease 2019; PRISMA: Preferred Reporting Items for Systematic Reviews and Meta-Analyses; CDC: Centers for Disease Control and Prevention; WHO: World Health Organization.
\end{abstract}

Ethics Approval and Consent to Participate

Not Applicable

\section{Competing Interest}

The authors declare that they have no conflict of interest to disclose.

\section{Availability of Data and Materials}

The authors confirm that the data supporting the findings of this study are available within the article.

\section{Authors' Contribution}

All authors contributed equally to the work presented in this paper.

\section{Acknowledgment}

Authors special thanks are extended to the staff of Faculty of Medicine, University of Muhammadiyah Malang, Malang East Java for their valuable support for this article.

\section{References}

1. Supriyanto S, Ernawaty E, Setyawan FEB, Lestari R. Enhancing family medicine practice in developing countries through a holistic-comprehensive model: a review. Indian Journal of Public Health Research \& Development. 2019; 10(10): 774-8.

2. Setyawan FEB. Pendekatan pelayanan kesehatan dokter keluarga (pendekatan holistik komprehensif). Sidoarjo: Zifatama Jawara; 2019.

3. Pritasari K. Public health and political commitment: learning toward comprehensive public health effort. Indonesia's current situation and challenges; 2019.

4. Supriyanto S, Setyawan FEB, Ernawaty E, Prayoga D. Kebijakan kesehatan dan analisis kebijakan. Sidoarjo: Zifatama Jawara; 2020. 
5. Wu C, Chen X, Cai Y, Xia J, Zhou X, Xu S, et al. Risk factors associated with acute respiratory distress syndrome and death in patients with coronavirus disease 2019 pneumonia in Wuhan, China. JAMA Internal Medicine. March 2020; 180 (7): 934-43.

6. Stojkoski V, Utkovski Z, Jolakoski P, Tevdovski D, Kocarev L. The socio-economic determinants of the coronavirus disease (COVID-19) pandemic. medRxiv; Posted April 17, 2020.

7. Abrams EM, Szefler SJ. COVID-19 and the impact of social determinants of health. The Lancet Respiratory Medicine. July 2020; 8.

8. Yanjun G, Hong D, Xinyi Z. Understanding the impact of the COVID19 pandemic on career development: insights from cultural psychology. Journal of Vocational Behavior. June 2020; 119: 103438.

9. Khenti A, Fréel S, Trainor R, Mohamoud S, Diaz P, Suh E, et al. Developing a holistic policy and intervention framework for global mental health. Health Policy and Planning. 2016; 31 (1): 37-45.

10. Roca A, Afolabi MO, Saidu Y, Kampmann B. Ebola: a holistic approach is required to achieve effective management and control. Journal of Allergy and Clinical Immunology. 2015; 135 (4): 856-67.

11. Vesely A. Theory and methodology of best practice research: a critical review of the current state. Central European Journal of Public Policy. 2011; 5 (2): 98-117.

12. Chandran P, Chin V, Harjivan C, Reeves M, Zhou Y. Detect, develop, and deliver: a holistic approach to managing outbreaks. Boston: Boston Consulting Group; 2020.

13. Secretariat of the Republic of Indonesia. Press statement of President of the Republic of Indonesia on government policy to handle the impacts of COVID-19 pandemic, thursday, 9 April 2020 at the Merdeka Palace, Jakarta. Jakarta: Secretariat of the Republic of Indonesia; 2020.

14. Respati T, Feriandi Y, Ndoen E, Raksanegara A, Djuhaeni H, Sofyan A, et al. A qualitative ecohealth model of dengue fever (DF) in Bandung, Indonesia. International Journal of Tropical Disease. 2018; 1 (1): 1-12.

15. Marchelin T. Government pays $\$ 1.5 \mathrm{~m}$ down payment for COVID-19 patients' treatment. 2020.

16. Centers for Disease Control and Prevention. Public health communicators: get your community ready. Atlanta: CDC; 2020.

17. Loignon C, Nouvet E, Couturier F, Benhadj L, Adhikari NKJ, Murthy $\mathrm{S}$, et al. Barriers to supportive care during the Ebola virus disease outbreak in West Africa: results of a qualitative study. PLOS ONE. 2018; 13 (9): e0201091.

18. Alonge O, Sonkarlay S, Gwaikolo W, Fahim C, Cooper JL, Peters DH. Understanding the role of community resilience in addressing the Ebola virus disease epidemic in Liberia: a qualitative study (community resilience in Liberia). Glob Health Action. 2019; 12 (1): 1662682.

19. Saha S, Islam M, Saha S, Uddin MJ, Rahman H, Das RC, et al. Designing comprehensive public health surveillance for enteric fever in endemic countries: importance of including different healthcare facilities. The Journal of Infectious Diseases. 2018; 218 (suppl_4): S227S231.

20. Craig AT, Joshua CA, Sio AR, Teobasi B, Dofai A, Dalipanda T, et al. Enhanced surveillance during a public health emergency in a resourcelimited setting: experience from a large dengue outbreak in Solomon Islands, 2016-17. PLOS ONE. 2018; 13 (6): e0198487.
21. Njuguna C, Jambai A, Chimbaru A, Nordstrom A, Conteh R, Latt A, et al. Revitalization of integrated disease surveillance and response in Sierra Leone post Ebola virus disease outbreak. BMC Public Health. 2019; 19: 364.

22. Levine M, Fraser M. Elements of a comprehensive public health response to the opioid crisis. Annals of Internal Medicine. 2018; 169 (10): 712 .

23. Kinsman J, Angrén J, Elgh F. Furberg M, Mosquera PA, Otero-García $\mathrm{L}$, et al. Preparedness and response against diseases with epidemic potential in the European Union: a qualitative case study of Middle East Respiratory Syndrome (MERS) and poliomyelitis in five member states. BMC Health Services Research. 2018; 18: 528.

24. Afayo R, Buga M, Alege JB, Akugizibwe P, Atuhairwe C, Taremwa IM. Performance of epidemic preparedness and response committees to disease outbreaks in Arua District, West Nile Region. Journal of Environmental and Public Health. 2019; 2019: 1-8.

25. Fatiregun AA, Isere EE. Epidemic preparedness and management: a guide on Lassa fever outbreak preparedness plan. Nigerian Medical Journal: Journal of the Nigeria Medical Association. 2017; 58 (1): 1-6.

26. Abraham T. Lessons from the pandemic: the need for new tools for risk and outbreak communication. Emerging Health Threats Journal. 2011; 4 (1): 7160.

27. Shen M, Xiao Y, Rong L. Modeling the effect of comprehensive interventions on Ebola virus transmission. Scientific Reports. 2015; 5: 15818.

28. Rabelo I, Lee V, Fallah MP, Massaquoi M, Evlampidou I, Crestani R, et al. Psychological distress among Ebola survivors discharged from an Ebola treatment unit in Monrovia, Liberia - a qualitative study. Frontiers in Public Health. 2016; 4: 142.

29. Logie CH, Turan JM. How do we balance tensions between COVID19 public health responses and stigma mitigation? learning from HIV research. AIDS and Behavior. 2020; 24: 2003-6.

30. Siu JY. Qualitative study on the shifting sociocultural meanings of the facemask in Hong Kong since the severe acute respiratory syndrome (SARS) outbreak: implications for infection control in the post-SARS era. Int J Equity Health. 2016; 15: 73.

31. Arslantas K, Hierink F, Teng A, Lammers F, Meijerink C, Veneman B. Improving community resilience through the development of an epidemic risk and priority framework. International Journal of Infectious Diseases. 2019; 79: 25-26.

32. Abdulkareem SA, Augustijn E-W, Filatova T, Musial K, Mustafa YT. Risk perception and behavioral change during epidemics: comparing models of individual and collective learning. PLOS ONE. 2020; 15(1): e0226483.

33. World Health Organization. Mental health and psychosocial considerations during the COVID-19 outbreak. Geneva: WHO; 2020.

34. Sepers CE, Fawcett SB, Hassaballa I, DiGennaro Reed F, Schultz J, Munodawafa D, et al. Evaluating implementation of the Ebola response in Margibi County, Liberia. Health Promotion International. 2019; 34 (3): 510-8.

35. Pan A, Liu L, Wang C, Guo H, Hao X, Wang Q, et al. Association of public health interventions with the epidemiology of the COVID-19 outbreak in Wuhan, China. JAMA. 2020; 323 (19): 1915-23. 